Provided for non-commercial research and education use. Not for reproduction, distribution or commercial use.

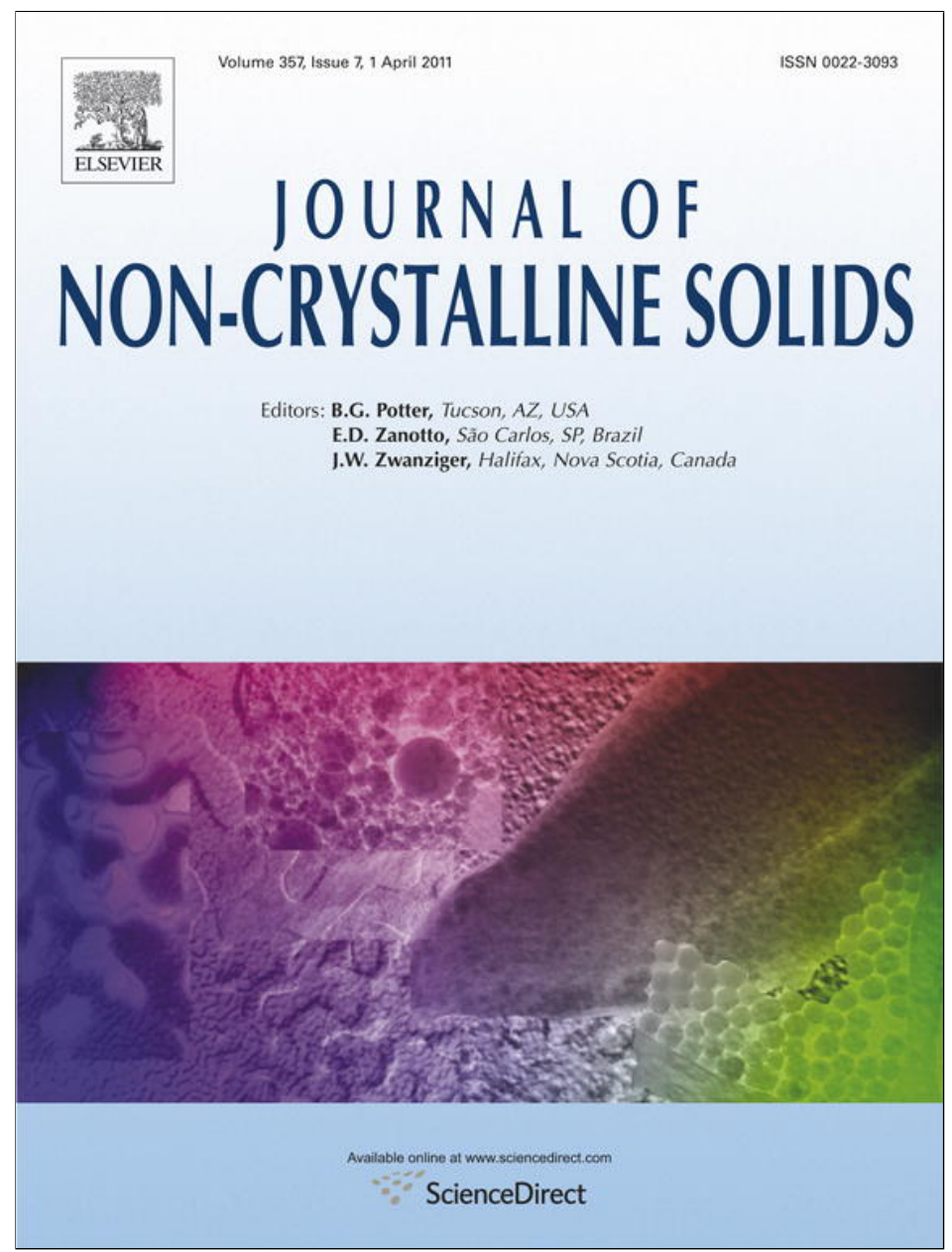

This article appeared in a journal published by Elsevier. The attached copy is furnished to the author for internal non-commercial research and education use, including for instruction at the authors institution and sharing with colleagues.

Other uses, including reproduction and distribution, or selling or licensing copies, or posting to personal, institutional or third party websites are prohibited.

In most cases authors are permitted to post their version of the article (e.g. in Word or Tex form) to their personal website or institutional repository. Authors requiring further information regarding Elsevier's archiving and manuscript policies are encouraged to visit:

http://www.elsevier.com/copyright 


\title{
Metallic glass nanofilms
}

\author{
M.Q. Jiang ${ }^{\mathrm{a}, \mathrm{b}}$, G.H. Duan ${ }^{\mathrm{a}}$, L.H. Dai ${ }^{\mathrm{a}, \mathrm{b}, *}$ \\ a State Key Laboratory of Nonlinear Mechanics, Institute of Mechanics, Chinese Academy of Sciences, Beijing 100190, PR China \\ b State Key Laboratory of Explosion Science and Technology, Beijing Institute of Technology, Beijing 100081, PR China
}

\section{A R T I C L E I N F O}

\section{Article history:}

Received 4 May 2010

Received in revised form 24 January 2011

Available online 23 February 2011

\section{Keywords:}

Metallic glass;

Nanofilm;

Structural stability;

Electron-transparency;

Shear bands

\begin{abstract}
A B S T R A C T
In this paper, we report for the first time the spontaneous formation of Zr-based metallic glass nanofilms by developed dynamic forced-shear-rupture technique of hat-shaped specimens. The obtained nanofilms have about $100 \mathrm{~nm}$ thickness and other two geometrical dimensions can reach micrometer scales. Their glassy nature and structural stability were solidly identified. It was found that electrons with the wavelength of less than 0.165 Å could make the metallic glass nanofilms transparent. Furthermore, it is clearly shown that shearbanding instability still afflicts such $100-\mathrm{nm}$-thick metallic glass nanofilms.
\end{abstract}

(c) 2011 Elsevier B.V. All rights reserved.

\section{Introduction}

Amorphous alloy nanofilms have attracted growing attention because they provide revolutionary advantages in the applications of electronic switch, photo/electro storage, flat panel display, magnetooptical device, etc. [1-4]. It has been well known that previous amorphous alloy films form mostly via sputtering or depositing of metal elements on substrates instead of the glass transition [1-7]. These amorphous films have manufacturing defects such as interfaces and cavities that generally lead to mechanical failure in service. Bulk metallic glasses (BMGs) represent a relatively young class of amorphous alloys with intriguing physical, chemical, and mechanical properties [8-15]. Defects underpinning plastic flow in their crystalline cousins, such as dislocations or grain boundaries, are not present. Instead, BMGs flow via a series of discrete atomic jumps around free-volume sites [16] or a subtle structural-rearrangement-type "flow event" within atomic cluster, increasingly commonly "shear transformation zones, STZs" $[17,18]$. The unique mechanism allows the plastic flow to occur at microscale or even nanoscale [19-23], which provides a feasible way to form metallic glass nanostructures. Recently, various metallic glass nanostructures such as wires, rods and spheres have been discovered, resorting to the highly localized plastic flow driven by force or heating [24-28]. It is noted that, however, these nanostructures are either zerodimensional (OD) or one-dimensional (1D). One interesting question naturally arises on whether two-dimensional (2D) alloy nanofilms with

\footnotetext{
* Corresponding author at: State Key Laboratory of Nonlinear Mechanics, Institute of Mechanics, Chinese Academy of Sciences, Beijing 100190, PR China. Tel.: +86 10 52843958; fax: +86 1082543977.

E-mail addresses: mqjiang@imech.ac.cn (M.Q. Jiang), lhdai@Inm.imech.ac.cn (L.H. Dai).
}

glassy structure can be sustained. If the answer is affirmative, the transparency and plastic flow of nanofilms are also interesting. In this study, a dynamic forced-shear-rupture (DFSR) method has been employed for fabrication of Zr-based metallic glass nanofilms. Their glassy nature and structural stability were confirmed with different characterizing tools. Furthermore, their electron-transparency and plastic flow mode were also investigated. Possible mechanisms of transparency and plastic flow have also been discussed.

\section{Experimental procedure}

A typical Vit $1\left(\mathrm{Zr}_{41.2} \mathrm{Ti}_{13.8} \mathrm{Cu}_{10} \mathrm{Ni}_{12.5} \mathrm{Be}_{22.5}\right)$ BMG was used for this study, because of its excellent glass-forming ability [29,30], high thermal stability against crystallization, a wide supercooled liquid region, superior mechanical properties and its potential as an advanced material [31] in contrast to other systems. Master alloy ingots were obtained by arc-melting of the elements $\mathrm{Zr}, \mathrm{Ti}, \mathrm{Cu}, \mathrm{Ni}$ and Be with a purity of $99.9 \%$ or better together under a Ti-gettered $\mathrm{Ar}$ atmosphere. To ensure homogeneity, the master alloy ingots were re-melted several times and subsequently suction-drawn into copper molds to form rods having a diameter of $8 \mathrm{~mm}$ and a length of $\sim 80 \mathrm{~mm}$, as shown in the inset to Fig. 1 . The glassy structure of rods was confirmed by X-ray diffraction in a Philip PW 1050 diffractometer using $\mathrm{Cu} K \alpha$ radiation. As can be seen in Fig. 1, the rod shows only broad diffraction maxima, revealing the glassy structure.

Hat-shaped specimen was firstly fabricated by Hartman et al. [32] and was used successfully for various crystalline alloys [33-35]. In the present study, hat-shaped specimens of BMGs were obtained by lathe machining of the as-cast Vit 1 rods. The dimension of hat-shaped specimen was specially designed, as shown in Fig. 2a, and fabricated specimen is presented in Fig. 2b. DFSR tests were performed with a split Hopkinson 


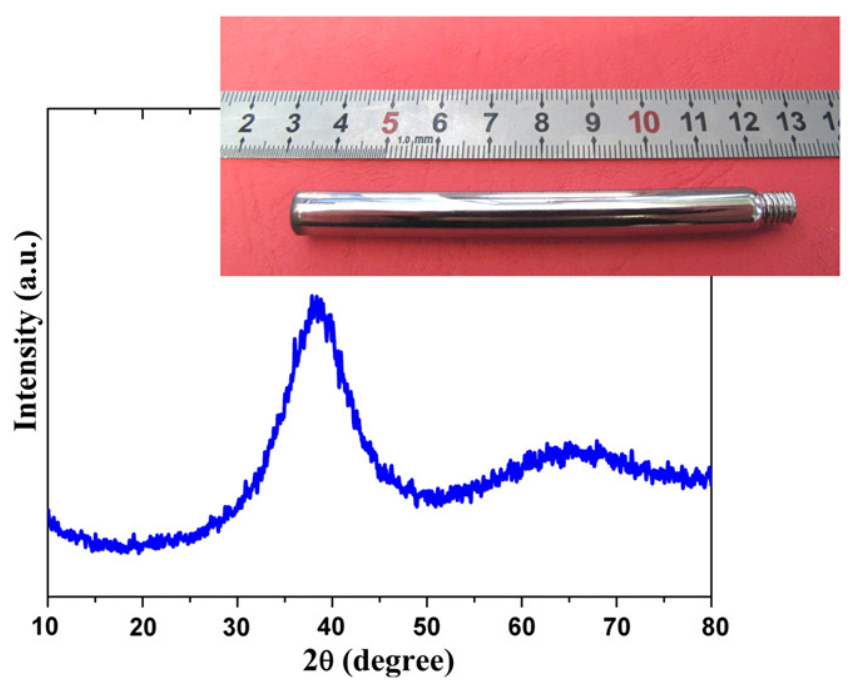

Fig. 1. XRD pattern of Vit 1 BMG rod $8 \mathrm{~mm}$ in diameter (inset).

pressure bar (SHPB) at room temperature. In DFSR tests, the hat-shaped specimen was sandwiched between the incident and the transmitted bars. The launched bullet driven by high-pressure gas was impacted onto the free end of the incident bar. At the moment of impact, the generated shock-wave in the incident bar compresses the top bar that is displaced into the bottom ring. This produces a shear-localization in the connection area between the bar and the ring. Such highly localization incurs a significant temperature rise and subsequently induces the formation of a perfect liquid layer $[20,23,36]$, as illustrated in Fig. 2c. With further shearing, cracks form along the shear band. During the crack advance, the fluid meniscus instability of the interface between the liquid layer and the crack occurs [37-39]. Owing to the wedging action of the top bar of hatshaped specimen, the liquid layer undergoes intense tension-rupture at the final stage, as illustrated in Fig. $2 \mathrm{~d}$.

The fractured specimen after DFSR testing is shown in Fig. 2b. An FEI Sirion high-resolution scanning electron microscopy (HRSEM) with spatial resolution of $1.5 \mathrm{~nm}$ was used to examine the forced shear-fracture zones (FSZs) of all the specimens. The compositions of both the as-cast and fractured surfaces were characterized by using an Energy Dispersive X-Ray (EDX) system (OXFORD INCA energy system) combined with the HRSEM. It is expected that metallic glass nanofilms could be formed in the FSZ. The glassy structure of the obtained nanofilms was identified with a high-resolution transmission electron microscopy (HRTEM) (JEOL JEM-2010 operated at $200 \mathrm{keV}$ ). In order to obtain individual nanofilms for TEM observation, we employed the ultrasonic vibration fragmentation technique. Experiments were performed as this procedure. First, we immersed the fractured specimens (see Fig. 2b) in an acetone solution. Then, we applied the ultrasonic vibration with the frequency of $40 \mathrm{kHz}$ and the

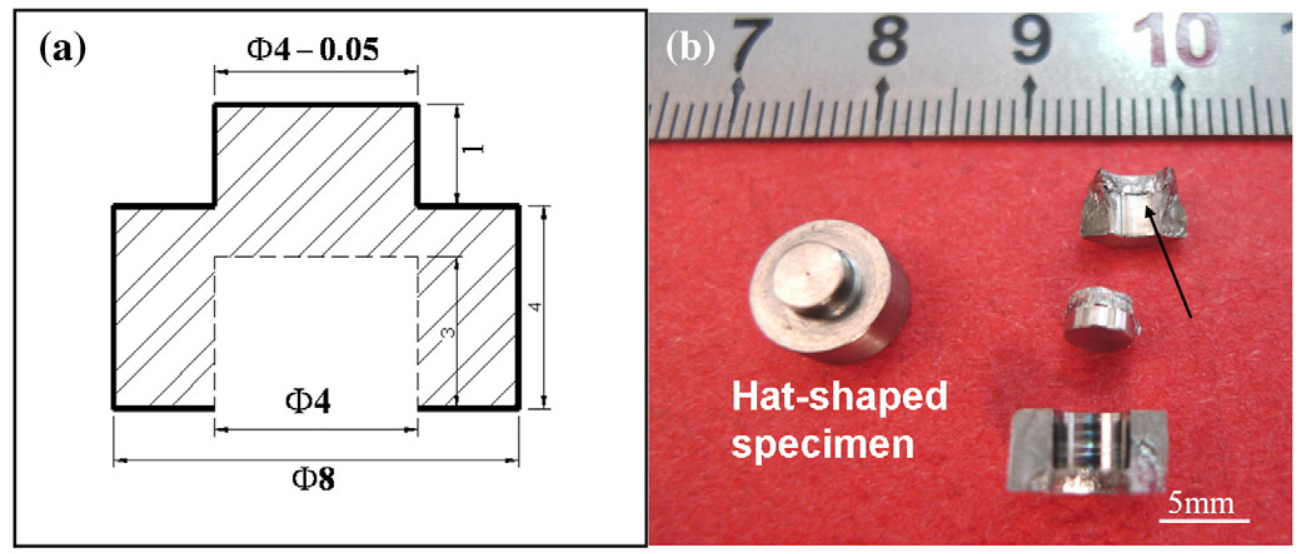

(c)

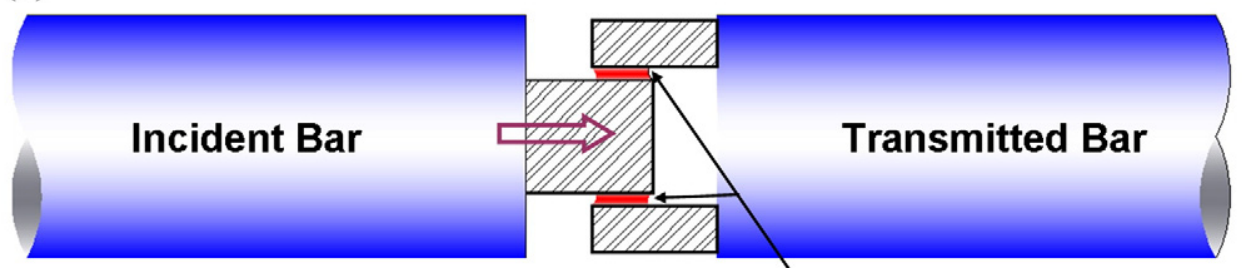

Liquid layers

(d)

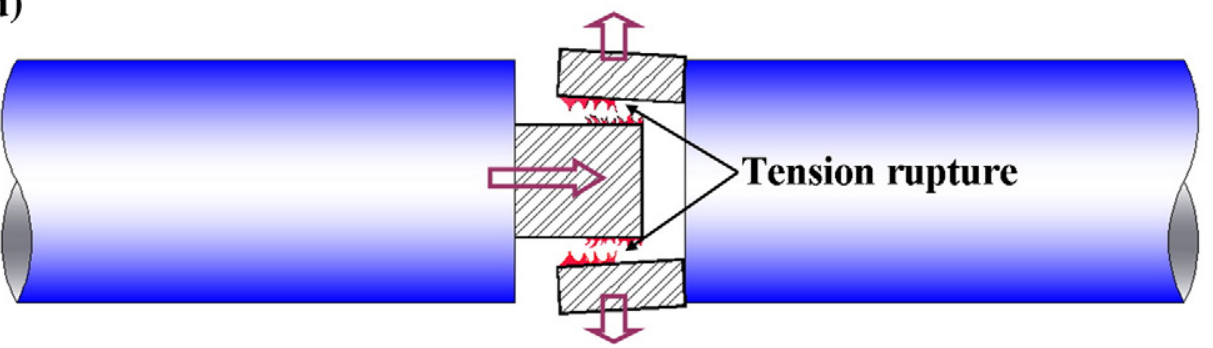

Fig. 2. (a-d). (a) Configuration of hat-shaped specimen (dimension in $\mathrm{mm}$ ), (b) the real specimen before and after testing, (c) formation of a fluid layer due to forced shearing, (d) tension fracture of the fluid layer, during which the fluid meniscus instability occurs. 
power of $100 \mathrm{~W}$ to the solution for ten minutes at the room temperature. Under the ultrasonic vibration, the nanofilms fragmentate and suspend in the solution. Finally, we dropped the suspension on a carbon film that covered a copper net using transferpette. The composition of nanofilms was identified by an EDX system (OXFORD INCA energy system) combined with the HRTEM.

\section{Results}

\subsection{Formation of Metallic glass nanofilms}

Fig. 3a presents the full-view of the FSZ of the hat-shaped specimen marked in Fig. 2b. The fracture patterns at different magnification in the FSZ are shown in Fig. 3(c-d). Microscopic cell- like vein patterns can be clearly observed in the FSZ, indicating the shear-predominated fracture process and the occurrence of the fluid meniscus instability [37-39]. As expected that, with the attendant vein patterns, many thin-films can indeed be observed, as shown in Fig. 3(b and c). Close-up views of the areas "D" and "E" in Fig. 3b are displayed in Fig. 3d and e, respectively. It is found that the size of thin-films can reach several to 20 or more micrometers. Fig. $3 \mathrm{f}$ is a high-magnification micrograph of an area marked "F" in Fig. 3e, clearly exhibiting that the thickness of thin film is about $100 \mathrm{~nm}$.

\subsection{Identification of glassy nature and its stability}

Fig. 4a shows a single piece of nanofilm on the carbon film. A closeup view of the marked region in Fig. 4a is shown in Fig. 4b. Fig. 4c is
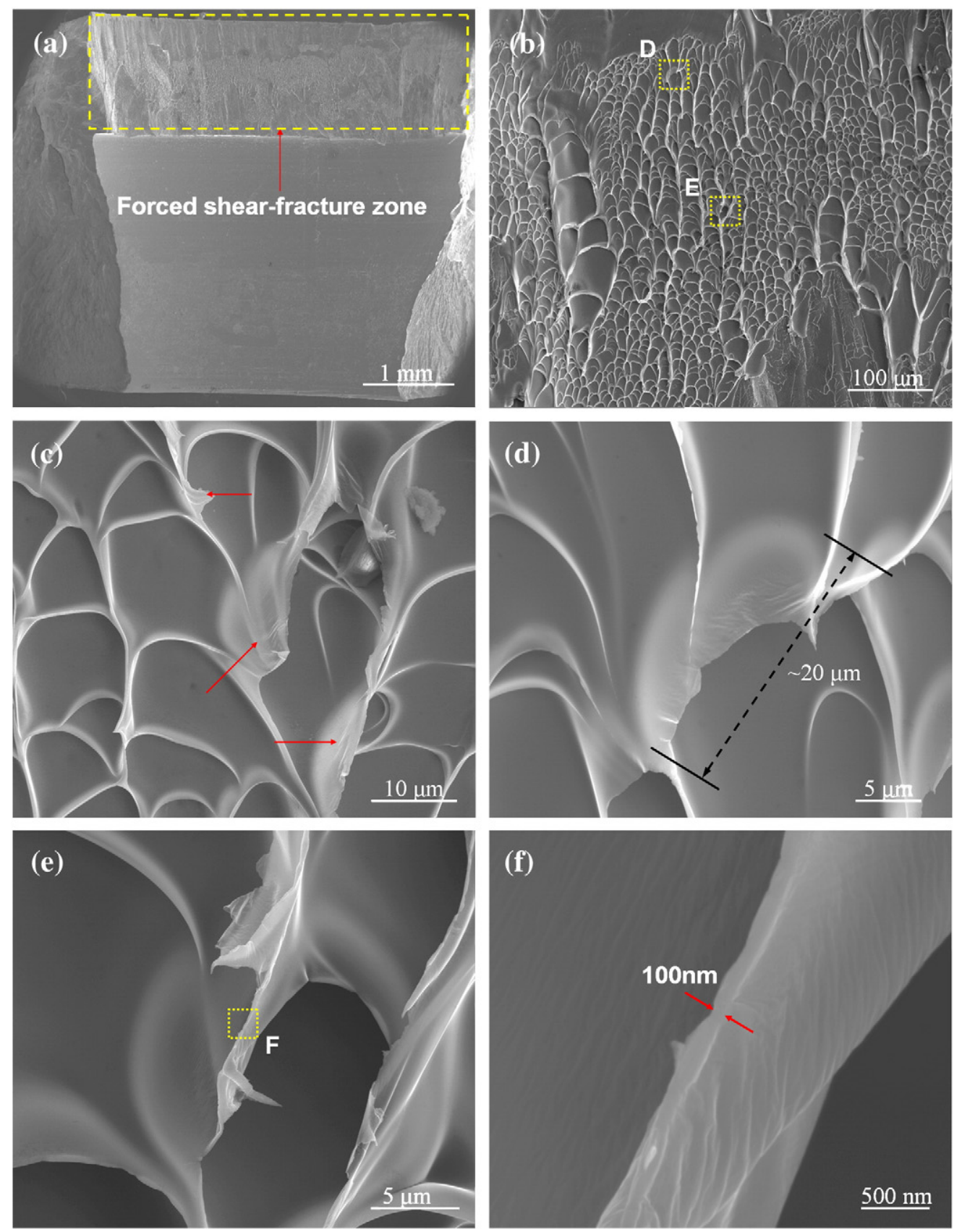

Fig. 3. (a-f). SEM micrographs showing the shear fracture feature of a hat-shaped specimen. (a) The full-view of a fractured specimen, (b) and (c) the forced shear-fracture zone at different magnification marked in (a), (d) and (e) details corresponding to areas "D" and "E" marked in (b), respectively, (f) magnified picture corresponding to area "F" marked in (e), clearly showing the $\sim 100$-nm-thick nanofilm. 


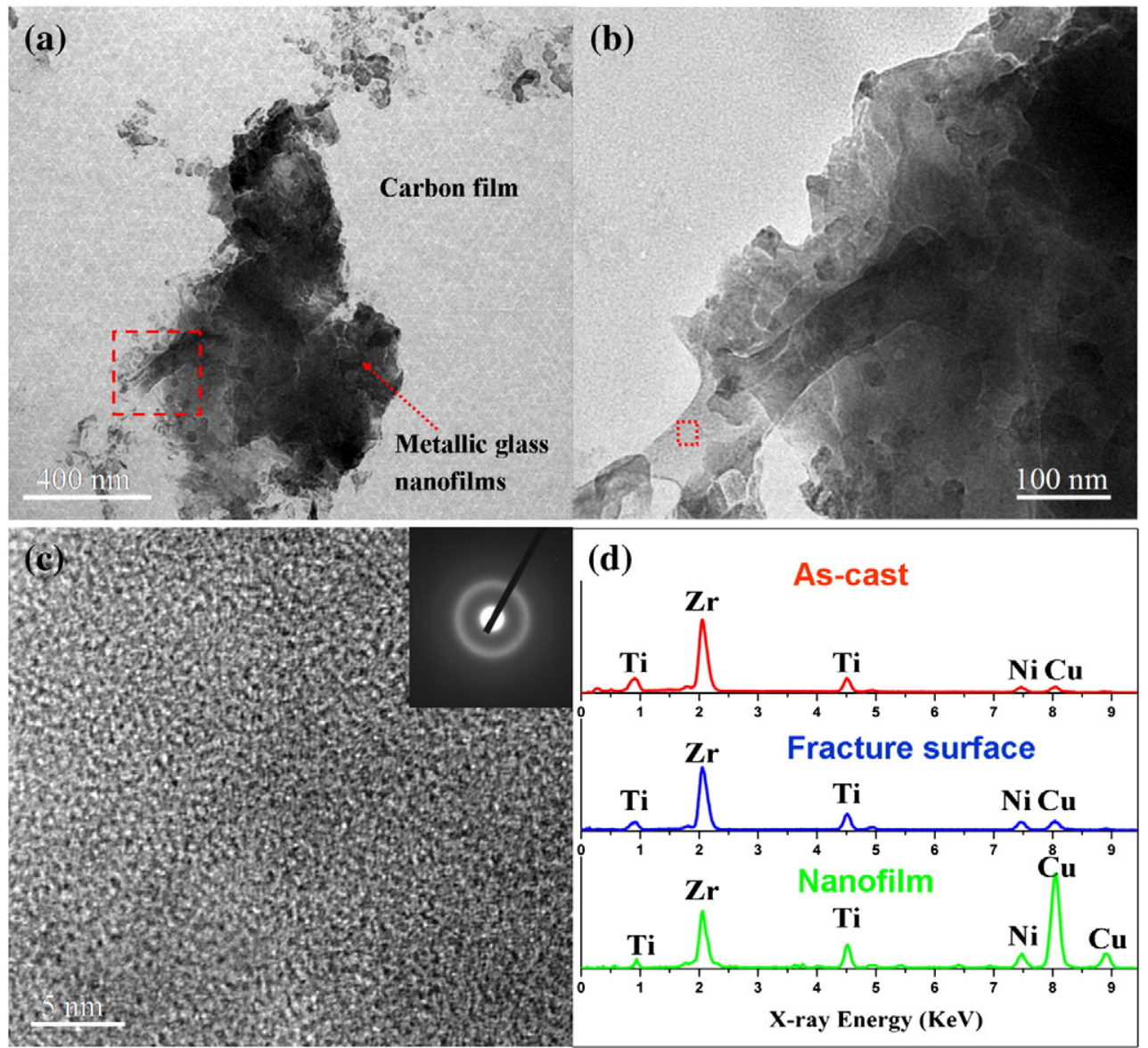

Fig. 4. (a-d). TEM and EDX result of metallic glass nanofilm. (a) A single piece of nanofilm on the carbon film, (b) the close-up view of the marked region in (a), (c) HRTEM image of area marked in (b) showing the long-range disorder atomic structure. Inset: corresponding electron diffraction pattern confirms that the nanofilm is entirely glassy, (d) EDX results obtained from the as-cast specimen, the fracture surface in Fig. 3(a), and the nanofilm in (a).

the HRTEM image of the thin area marked in Fig. 4b, displaying mazelike patterns without any crystalline fringes. The inset image shows the corresponding electron diffraction pattern that is a halo ring. This confirms further that the nanofilms are entirely glassy. The results of the EDX for the as-case, fracture surfaces and nanofilms are presented in Fig. 4d, indicating that their compositions are identical. It can be seen that the peaks of only $\mathrm{Zr}, \mathrm{Ti}, \mathrm{Cu}$, and $\mathrm{Ni}$ are identified, and the lightest element Be cannot be detected. In addition, compared with the as-cast specimen and the fracture surfaces, the metallic glass nanofilm has relatively high $\mathrm{Cu}$ content, we believe, which is due to the effect of $\mathrm{Cu}$ net in the background.

From the thermodynamic point of view, metallic glasses are in a metastable state and will undergo crystallization with the supply of sufficient exoteric energy $[40,41]$. The partially or fully crystallization can changes their properties; hence attention to the structural stability of the metallic glass nanofilms is also important. Fig. 5 shows a series of micrographs of the atomic structure of metallic glass nanofilm by in situ HRTEM observations and corresponds to the exposition of $200 \mathrm{keV}$ electrons for 0 (initial), 30, 60, and $90 \mathrm{~min}$, respectively. From these micrographs, no significant nano/crystallization can be observed.

\subsection{Electron-transparency}

In particular, it is noticed that the metallic glass nanofilms seem transparent to some extent, as shown in Figs. 3(c-e) and 4(a-b), when exposed to the high energy electrons. As for the present $\sim 100 \mathrm{~nm}$ of nanofilm, it is interesting to investigate the effect of the accelerating voltage of electrons on the transparency of the metallic glass nanofilm. Fig. 6(a-d) shows the metallic glass nanofilm under the accelerating voltage of $15 \mathrm{keV}, 10 \mathrm{keV}, 5 \mathrm{keV}$ and $2 \mathrm{keV}$, respectively. It can be seen that with the decrease of the accelerating voltage of electrons, the nanofilm opacify gradually. The critical voltage from transparency to opacity is about $5 \mathrm{keV}$, as indicated in Fig. 6c.

\subsection{Deformation mode}

Fig. 7 shows HRSEM images of the fracture feature of asfabricated metallic glass nanofilm (see Fig. 6a) after the ultrasonic vibration fragmentation. Fig. 7a presents the full-view of the fractured nanofilm that is very similar to a fractured windowglass, showing a typical brittle fracture mode. Fig. 7b is a highmagnification image of an area marked in Fig. 7a. It can be seen from this image that the brittle fracture is due to shear bands formation. Fig. 7(c and d) presents a precise picture on how a shear band induces a mode III crack. Obviously, the shearing or subsequent cracking is along the thickness direction. Such failure mode further confirms that the nanofilm has about $100 \mathrm{~nm}$ thickness, as measured in Fig. 7c. Fig. 7d clearly shows a nanometer-sized shear band ahead of the crack.

\section{Discussion}

HRSEM observations (Figs. 3f and 7c) clearly indicate that the thickness-value $(\sim 100 \mathrm{~nm})$ of the metallic glass nanofilms has the same order of magnitude as the thermal diffusion length in BMGs $[20,36]$. Evidently, the observed thin films are the result of the 

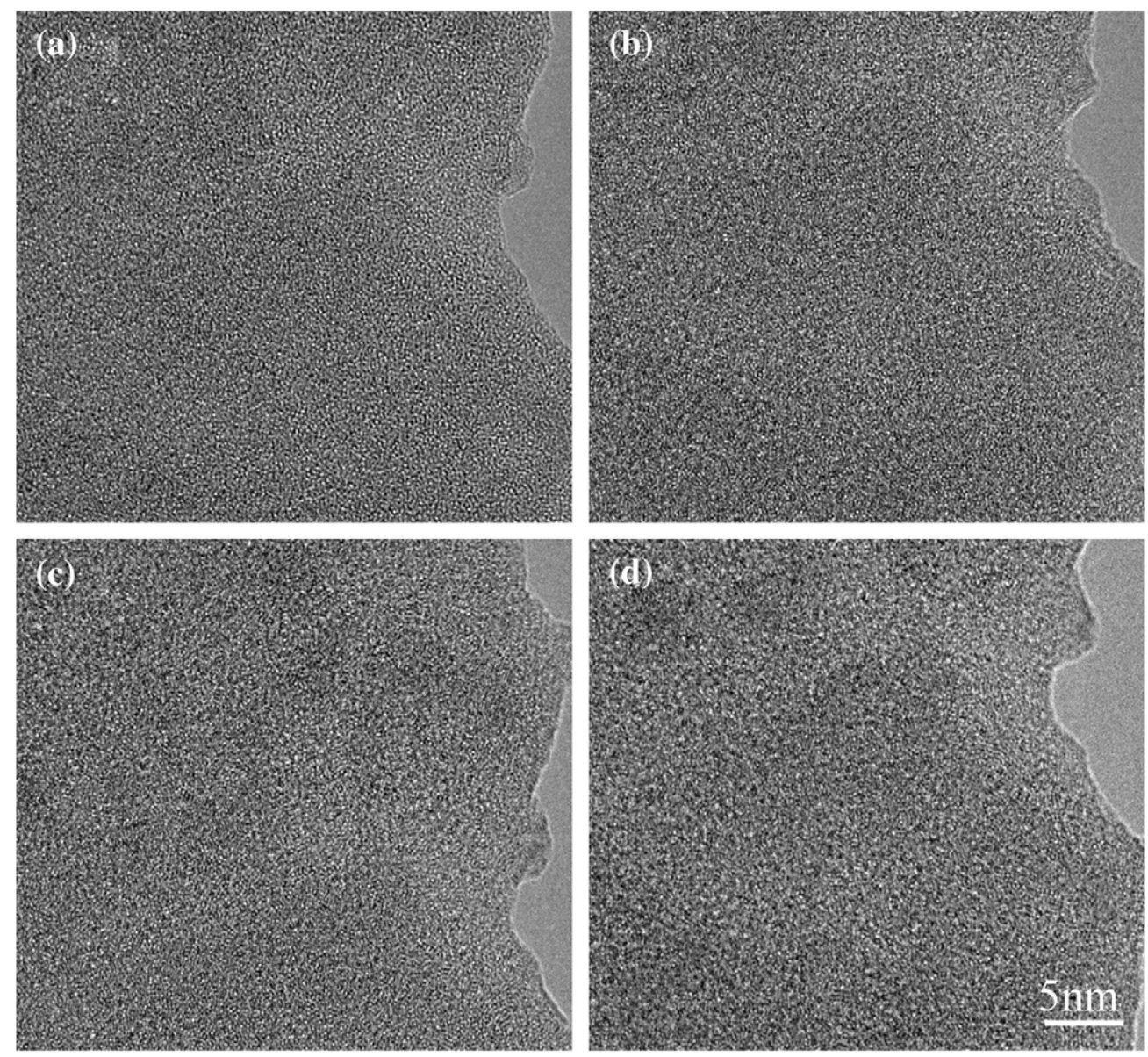

Fig. 5. (a-d). In situ HRTEM observations of metallic glass nanofilm: (a) 0 min (initial structure), (b) $30 \mathrm{~min}$, (c) $60 \mathrm{~min}$ and (d) $90 \mathrm{~min}$.

cooling and solidification of the liquid layer. It was estimated that the cooling rate $\left(\sim 10^{6} \mathrm{~K} / \mathrm{s}\right)$ greatly exceeds the critical cooling rate for the glass formation ( 1-10 K/s for typical Zr-based BMGs [24]). This ensures the glassy structure of the nanofilm formed in the FSZ $[24,27]$. The present DFSR method provides a simple but useful way to obtain metallic glass nanofilms, during which two necessary factors furnish the dominant contribution. This first is the formation of the perfect liquid layer ahead of the crack. The second is the fast drawing and cooling of the liquid layer when the crack propagates. Our finding (see Figs. 4 and 5) provides powerful evidence that the disordered atomic configuration of metallic glasses can be sustained in the 2D-nanostructures, even under the long-term activation of high energy electrons. Such stability of metallic glass nanofilm is believed to be due to a combination of two factors:

(i) Most electrons with extremely high energy can pass easily through the present metallic glass nanofilm, even lattice in disordered state.

(ii) Heat resulting from inelastic interactions between the beam and matrix electrons at defects can diffuse quickly out of the nanofilm because the extremely thin size of nanofilm has significantly enhanced thermal diffusion.

The metallic glass nanofilm has the critical voltage of about $5 \mathrm{keV}$ from transparency to opacity, as seen in Fig. 6c. According to the deBrogile relationship [42], electrons of $5 \mathrm{keV}$ energy have a wavelength of $0.165 \AA$. This critical wavelength of incident light is about one order of magnitude lower than both the radius of the smallest atoms (Be) and the free volume defect sizes [19,43]. Therefore, such high-energy electrons are effectively transmitting through the metallic glass nanofilm about $100 \mathrm{~nm}$ in thickness. If we consider roughly that the $100 \mathrm{~nm}$ is the optical penetration depth (OPD) $d_{1}$, the optical absorption coefficient is calculated by [44]

$\alpha \equiv \frac{1}{d_{1}}=10^{5} \mathrm{~cm}^{-1}$

This indicates that metallic glasses are strong absorber mediums because of the long-range disorder lattice structure.

It is well known that room-temperature ductility that is a desirable property for high-strength BMGs is determined by deformation modes. Highly localized flow mode, i.e. single or few shear bands, usually renders macroscopic brittle fracture [23,37,45], whereas multiple shear bands [46] or homogeneous flow [47] contribute to larger ductility. Recently, Donohue et al. [5] and Wang et al. [6] reported that shear bands can be suppressed in amorphous alloy nanofilms of less than $100 \mathrm{~nm}$ in thickness. However, their nanofilms are constrained by crystalline metal/alloy layers, suppressing any sudden failure. In our current case, the metallic glass nanofilm is almost unconstrained. The results (see Fig. 7) of the ultrasonic vibration fragmentation provided a solid evidence for shear-banding-mode deformation in the metallic glass film down to $100 \mathrm{~nm}$ thickness. The occurrence of shear banding in the present metallic glass nanofilm can be understood in terms of the agedrejuvenation-glue-liquid shear band model [48]. It predicts a critical "plastic localization" length scale $L_{i n c}$ in order for STZs $[17,18]$, to develop into mature shear bands [6,48]:

$L_{\text {inc }}=\frac{\alpha C_{v}^{2}\left(T_{g}-T_{\text {env }}\right)^{2}}{\tau_{\text {glue }}^{2} c_{s}}$, 

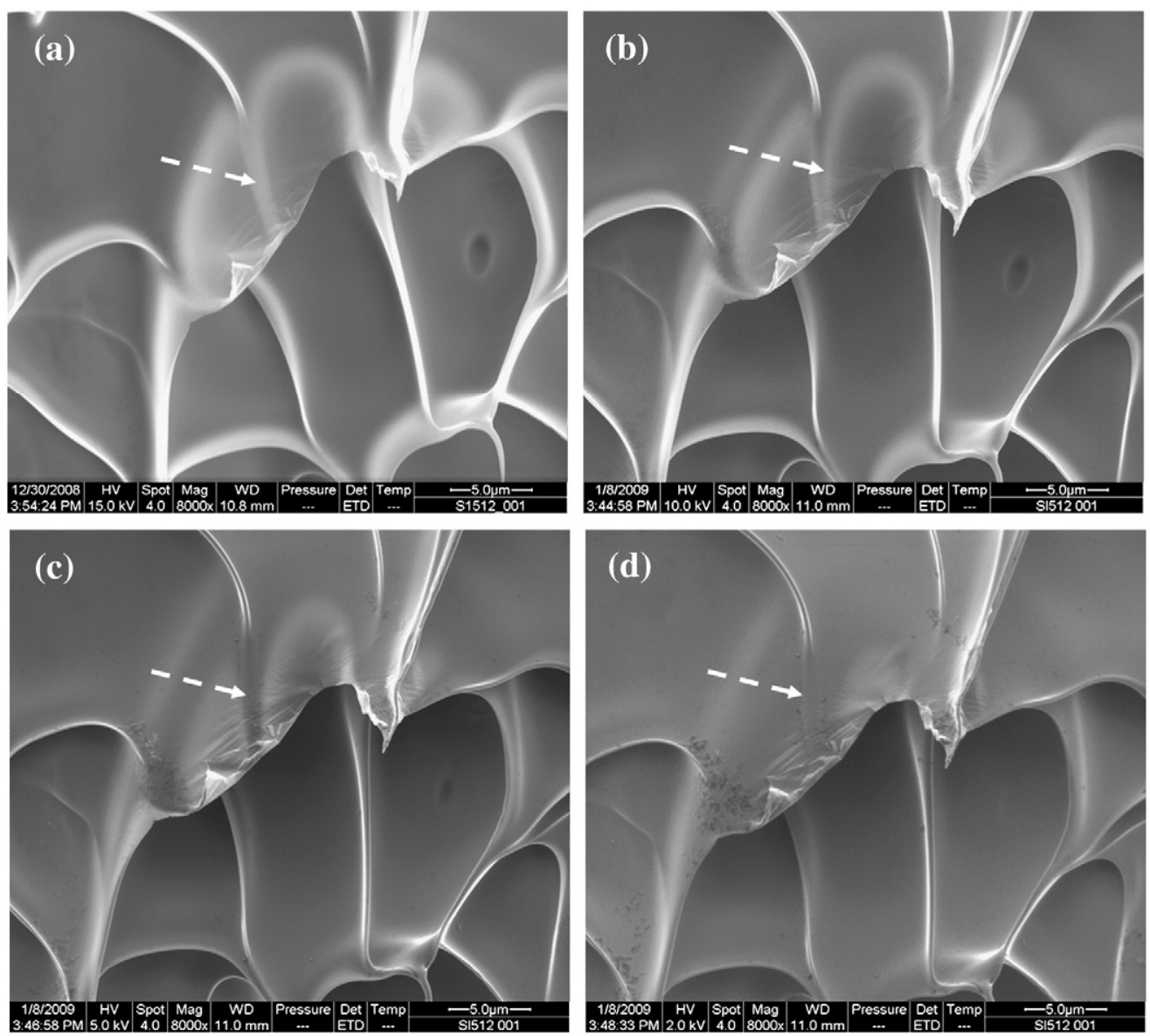

Fig. 6. (a-d). Effect of accelerating voltage: (a) $15 \mathrm{keV}$, (b) $10 \mathrm{keV}$, (c) $5 \mathrm{keV}$ and (d) $2 \mathrm{keV}$ of electrons on the transparency of metallic glass nanofilm.
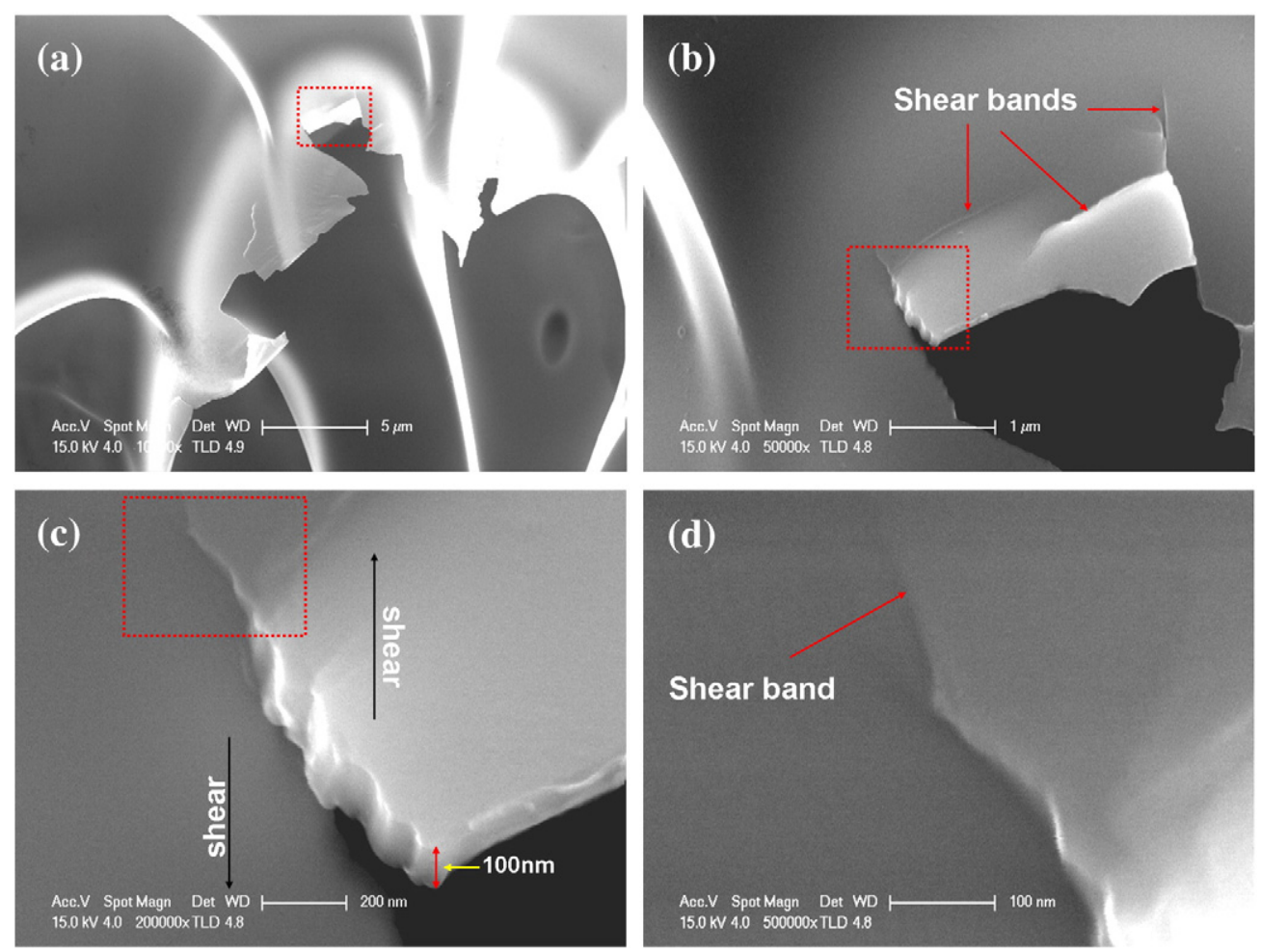

Fig. 7. (a-d). HRSEM micrographs showing the failure mode of metallic glass nanofilm. (a) The full-view of the fractured nanofilm, (b-d) details corresponding to areas marked in (a), (b) and (c), respectively, exhibiting shear band instability ahead of the crack. 
where $\alpha$ is the thermal diffusivity, $C_{v}$ is the volumetric specific heat, $T_{g}$ is the glass transition temperature, $T_{e n v}$ is the environment temperature, $\tau_{\text {glue }}$ is the stress required to maintain quasi-steady-state propagation of an embryonic shear band, and $c_{s}$ is the shear wave speed. For the present Vit 1 BMGs [23], Eq. (2) gives $L_{i n c}<10 \mathrm{~nm}$. Therefore, the characteristic size $(\sim 100 \mathrm{~nm}$ thick) of the stressed metallic glass nanofilm exceeds the $L_{\text {inc }}$. Under this condition, shear localization will be able to develop in a usual fashion. In addition, it must be pointed out that the ultrasonic vibration is actually a dynamic mechanical loading, in which the heating and cavitation effects can be ignored. Our previous works have revealed that the shear band instability is more probable under higher-strain-rate loading $[23,49]$.

\section{Conclusions}

The dynamic forced-shear-rupture (DFSR) tests of hat-shaped specimens were specially designed with a split Hopkinson pressure bar. During DFSR, the Zr-based metallic glass nanofilms can be spontaneously formed due to the fluid meniscus instability and accompanying tension stress. The characteristic thickness of metallic glass nanofilm is measured to be about $100 \mathrm{~nm}$. The ultrasonic vibration fragmentation method was adopted to obtain individual metallic glass nanofilm. Their glassy nature and the structural stability were identified by HRTEM combined with EDX. Very interestingly, it is found that the obtained nanofilms are electrontransparent. The critical wavelength of incident electron beam was determined to be $\sim 0.165 \AA$. Finally, the deformation mode of such 100 -nm-sized metallic glass film was investigated, during which the underlying mechanism was briefly discussed.

\section{Acknowledgements}

Financial support is from the NSFC (Grants Nos. 10725211, 11002144 and 11021262), the NSAF (Grant No. 10976100), the National Key Basic Research Program of China (Grant No. 2009CB724401), and the Key Project of Chinese Academy of Sciences (No. KJCX2-YW-M04). We are highly grateful to two anonymous reviewers for their helpful comments, which have improved our manuscript significantly.

\section{References}

[1] V. Bulovlć, G. Gu, P.E. Burrows, S.R. Forrest, Nature 380 (1996) 29.

[2] A.V. Kolobov, P. Fons, A.I. Frenkel, A.L. Ankudinov, J. Tominaga, T. Uruga, Nat. Mater. 3 (2004) 703
[3] E. Mytilineou, S.R. Ovshinsky, B. Pashmakov, D. Strand, D. Jablonski, J. Non-Cryst. Solids 352 (2006) 1991

[4] S.M. Hamidi, M.M. Tehranchi, M. Ghanaatshoar, M. Moradi, S.M. Mohseni, J. Non-Cryst. Solids 354 (2008) 5178.

[5] A. Donohue, F. Spaepen, R.G. Hoagland, A. Misra, Appl. Phys. Lett. 91 (2007) 241905.

[6] Y.M. Wang, J. Li, A.V. Hamza, T.W. Barbee Jr., PNAS 104 (2007) 11155.

[7] K.T. Liu, J.G. Duh, J. Non-Cryst. Solids 353 (2007) 1060.

[8] A.L. Greer, Science 267 (1995) 1947.

[9] W.L. Johnson, JOM 54 (2002) 40

[10] W.H. Wang, C. Dong, C.H. Shek, Mater. Sci. Eng. R. 44 (2004) 45

[11] M.F. Ashby, A.L. Greer, Scr. Mater. 54 (2006) 321.

[12] J. Eckert, J. Das, S. Pauly, C. Duhamel, J. Mater. Res. 22 (2007) 285.

[13] A. Inoue, N. Nishiyama, MRS Bull. 32 (2007) 651.

[14] C.A. Schuh, T.C. Hufnagel, U. Ramamurty, Acta Mater. 55 (2007) 4067.

[15] J. Schroers, Adv. Mater. 22 (2010) 1566.

[16] F. Spaepen, Acta Metall. 25 (1977) 407.

[17] A.S. Argon, Acta Metall. 27 (1979) 47.

[18] M.L. Falk, Science 318 (2007) 1880.

[19] J. Li, F. Spaepen, T.C. Hufnagel, Philos. Mag. 82 (2002) 2623

[20] Y. Zhang, A.L. Greer, Appl. Phys. Lett. 89 (2006) 071907.

[21] D. Pan, A. Inoue, T. Sakurai, M.W. Chen, PNAS 105 (2008) 14769.

[22] M.Q. Jiang, W.H. Wang, L.H. Dai, Scr. Mater. 60 (2009) 1004

[23] M.Q. Jiang, L.H. Dai, J. Mech. Phys. Solids 57 (2009) 1267.

[24] K.S. Nakayama, Y. Yokoyama, G. Xie, Q.S. Zhang, M.W. Chen, T. Sakurai, A. Inoue, Nano Lett. 8 (2008) 516.

[25] G. Kumar, H.X. Tang, J. Schroers, Nature 457 (2009) 868.

[26] Y.H. Liu, K. Wang, D. Pan, H. Wang, K. Nakayama, A. Inoue, W.H. Wang, M.W. Chen, Mater. Trans. 50 (2009) 1890

[27] X.X. Xia, W.H. Wang, A.L. Greer, J. Mater. Res. 24 (2009) 2986

[28] K.S. Nakayama, Y. Yokoyama, T. Ono, M.W. Chen, K. Akiyama, T. Sakurai, A. Inoue, Adv. Mater. 22 (2010) 872.

[29] A. Peker, W.L. Johnson, Appl. Phys. Lett. 63 (1993) 2342.

[30] A. Inoue, Mater. Trans., JIM 36 (1995) 866.

[31] W.L. Johnson, Curr. Opin. Solid State Mater. 1 (1996) 383.

[32] K.H. Hartman, H.D. Kunze, L.W. Meyers, Shock Waves and High-Strain-Rate Phenomena in Metals, in: M.A. Meyers, L.E. Murr (Eds.), Plenum Press, 1981.

[33] L.W. Meyers, S. Manwarning, in: Metallurgical Applications of Shock-wave and High-strain-rate Phenomena, Marcel Dekker, New York, 1986.

[34] M.A. Meyers, V.F. Nesterenko, J.C. LaSalvia, Q. Xue, Mater. Sci. Eng. A317 (2001) 204.

[35] M.T. Pérez-Prado, J.A. Hines, K.S. Vecchio, Acta Mater. 49 (2001) 2905.

[36] J.J. Lewandowski, A.L. Greer, Nat. Mater. 5 (2006) 15.

[37] M.Q. Jiang, Z. Ling, J.X. Meng, L.H. Dai, Philos. Mag. 88 (2008) 407.

[38] F. Spaepen, Acta Metall. 23 (1975) 615

[39] A.S. Argon, M. Salama, Mater. Sci. Eng. 23 (1976) 219.

[40] H. Chen, Y. He, G.J. Shiflet, S.J. Poon, Nature 367 (1994) 541.

[41] J.J. Kim, Y. Choi, S. Suresh, A.S. Argon, Science 295 (2002) 654.

[42] M. Ohring, The Materials Science of Thin Film, 2nd edAcademic Pre, New York, 2001.

[43] K.M. Flores, E. Sherer, A. Bharathula, H. Chen, Y.C. Jean, Acta Mater. 55 (2007) 3403.

[44] M. Born, E. Wolf, Principles of optics: Electromagnetic Theory of Propagation, Interference and Diffraction of Light, 17th (expanded) edCambridge University Press, Cambridge, 1999.

[45] Z.F. Zhang, J. Eckert, L. Schultz, Acta Mater. 51 (2003) 1167.

[46] J. Schroers, W.L. Johnson, Phys. Rev. Lett. 93 (2004) 255506.

[47] D.C. Jang, J.R. Greer, Nat. Mater. 9 (2010) 215.

[48] F. Shimizu, S. Ogata, J. Li, Acta Mater. 54 (2006) 4293.

[49] L.F. Liu, L.H. Dai, Y.L. Bai, B.C. Wei, J. Non-Cryst. Solids 351 (2005) 3259. 